\title{
Producing Flexible Nurses: How Institutional Texts Organize Nurses' Experiences of Learning to Work on Redesigned Nursing Teams (Préparer des infirmières polyvalentes : comment des documents officiels orientent les expériences d'apprentissage des infirmières en fonction du travail au sein d'équipes reconfigurées)
}

\author{
Diane L. Butcher \\ University of Victoria, dbutcher447@yahoo.ca \\ Karen MacKinnon \\ University of Victoria, kamackin@uvic.ca \\ Anne W. Bruce \\ University of Victoria, abruce@uvic.ca
}

Follow this and additional works at: https://qane-afi.casn.ca/journal

Part of the Educational Leadership Commons, and the Nursing Commons

\section{Recommended Citation}

Butcher, Diane L.; MacKinnon, Karen; and Bruce, Anne W. (2018) "Producing Flexible Nurses: How Institutional Texts Organize Nurses' Experiences of Learning to Work on Redesigned Nursing Teams (Préparer des infirmières polyvalentes : comment des documents officiels orientent les expériences d'apprentissage des infirmières en fonction du travail au sein d'équipes reconfigurées)," Quality Advancement in Nursing Education - Avancées en formation infirmière: Vol. 4: Iss. 1, Article 2.

DOI: https://doi.org/10.17483/2368-6669.1132

This Article is brought to you for free and open access by Quality Advancement in Nursing Education - Avancées en formation infirmière. It has been accepted for inclusion in Quality Advancement in Nursing Education - Avancées en formation infirmière by an authorized editor of Quality Advancement in Nursing Education - Avancées en formation infirmière. 
The impetus for this research evolved out of tensions that arose from the primary author's experiences teaching in a practical nurse program while in graduate school. Feelings of unsettledness and chafing occurred within the teaching context, related to expectations to teach from a content-driven, skills-based curriculum, focused on expediting job-ready nurses into the workforce. Utilizing Dorothy Smith's (1987, 1990, 2005, 2006) Institutional Ethnography (IE) as a lens, this chafing was interpreted as a disjuncture created out of two competing or contradictory experiences of reality. How could one reconcile teaching with the awareness that various pedagogical approaches, philosophical underpinnings, and/or theories from nursing literature did not prevail within the practical nurse educational realm? Further, how did practical nursing education align with nursing disciplinary knowledge and values?

This disjuncture further evolved as questions arose about practical nurse education and educational silos among baccalaureate and diploma (practical) nurse programs. How might expectations for collaboration and teamwork in practice influence expectations for teaching future students to support professional practice? Reflecting on experiences of teaching in two practical nurse programs, there appeared to be little communication between instructors of practical nurse $(\mathrm{PN})$ and registered nurse $(\mathrm{RN})$ programs; nor could instructors simultaneously teach in both programs (even when both programs were offered within a single institution). RNs interested in teaching seem to declare themselves as either practical or registered nurse educators, and teaching positions at universities and colleges often vary in their requirements for faculty and instructors for each program. What assumptions, questions, or concerns might there be among each group of nurses ${ }^{1}$ toward the other? Worth noting was that leaders of both programs sought RNs to teach in their programs, but students were not provided with any clinical experiences with students of other programs.

\section{Background and Significance}

Shifts in global health care landscapes have occurred in relation to widespread health professional shortages, economic constraints, calls for greater efficiencies, and expectations for inter-professional practice, which have stimulated the development of new care models for the delivery of nursing care (MacKinnon, Butcher, \& Bruce, 2018). With these shifts to team-based care models, RNs and licensed practical nurses (LPNs) report increasingly overlapping scopes of practice, which creates ambiguity and confusion about their roles.

Intersecting discourses of inter-professional collaboration, teamwork, lean thinking, efficiency, task shifting, and cost all stress that we must work towards blurring roles and overlapping scopes of practice to collaboratively provide high-quality (sustainable) patient care (College of Registered Nurses of BC [CRNBC], 2012; Joosten, Bongers, \& Janssen, 2009; Health Professions Council, 2001; Province of British Columbia, 2016a; 2016b; 2016c; World Health Organization [WHO], 2008). Thus, while nurses themselves have expressed concern about role ambiguity negatively affecting their ability to care for patients (Butcher, MacKinnon, Bruce, Gordon, \& Koning, 2017), this blurring of roles coupled with increasingly shared practice scopes is very much the intention across numerous contexts.

\footnotetext{
${ }^{1}$ Through legislation, nurses in Canada are categorized as either registered nurses (RNs), registered psychiatric nurses (RPNs), or practical or vocational nurses (LPNs). Registered psychiatric nurses only exist in the western provinces of BC, Alberta, Saskatchewan, and Manitoba. In Ontario, LPNs are referred to as Registered Practical Nurses (RPNs). In this paper, the term nurse refers to both practical and registered nurses unless differentiated.
} 
Nurses are regulated as three separate professions (registered nurse, licensed practical nurse, registered psychiatric nurse) according to one provincial government (Province of British Columbia, 2016d). However, the government of British Columbia (Health Professions Council, 2001), in their scope of practice reform initiatives, suggests that "a regulatory framework of overlapping scopes of practice and narrowly defined [restricted activities] creates a system which offers greater choice and accessibility to health care services at lower costs" (p. 32). One goal outlined in the $\mathrm{BC}$ health policy domain is to decrease exclusivity of professional regulatory groups and encourage "the addition or substitution of various mixes of skills for the services of the professional practitioner" (Health Professions Council, 2001, p. 34) by utilizing teams for the provision of health care.

What is less clear is how disciplinary knowledge intersects with the reassignment or sharing of various tasks, skills, or roles among professions and disciplines. The redistribution of tasks and creation of flexible workers is echoed at a global level, where WHO (2008) leaders suggest that one response to the shortage of health care workers is to reallocate various tasks. This task-shifting occurs as "specific tasks are moved, where appropriate, from highly qualified health care workers to health care workers with less training and fewer qualifications in order to make more efficient use of the available human resources" (WHO, 2008, p. 2).

A focus on tasks or skills also raises questions regarding whether the development of professional nursing practice is supported when students transition into the work environment. In an evolutionary concept analysis of nursing professional practice, Fraser (2011) outlines a definition of nursing professional practice as including: 1) a collection of traits (including selfregulation, autonomy, ethics, continuing competence, and disciplinary knowledge); 2) a way of being (including service, collaboration, leadership, and innovation); and 3) a label for the practice environment, which supports the previous two points. Significantly, Fraser suggests that:

these environments are characterized by interprofessional collaboration, a nursing care delivery model based on research related to the context of practice, the nurses' ability to practice autonomously according to professional standards and ethics, access to nurses in leadership positions, opportunities for continuing competence development... (p. 42)

Thus, organizations are expected to develop professional practice environments that encourage lifelong learning and continued development of the individual nurse. Professional care models that rely on RNs to provide significant amounts of nursing care (who also have considerable discretion in carrying out their work) requires organizations to recognize that nursing practice requires a certain level of education and to provide on-going organizational support, leadership, and recognition of nurses' work (Dubois et al., 2012). In contrast, functional care models view nursing as tasks that can be subdivided among various types of workers, focus on utilizing workers in flexible ways, and "draw more significantly on LPNs and assistant staff to deliver nursing services" (Dubois et al., 2012, p. 11). Fraser (2011) notes how nurse wellbeing is related to on-going structural and organizational support for professional practice, which includes organizational identification of professional nursing as a distinct service with institutional value.

Researchers have provided some insights into patient care team structure and outcomes. Studies have shown that care models with more educated and experienced nurses (Aiken, Clarke, Cheung, Sloane, \& Silber, 2003; McGillis Hall, Doran, \& Pink, 2004), more RN care hours (Lankshear, Sheldon, \& Maynard, 2005), and less fatigued, burdened nurses (Aiken, Clarke, 
Sloane, Sochalski, \& Silber, 2002; Rogers et al., 2004) are associated with positive outcomes and enhanced patient safety. Two systematic reviews exploring relationships between nurse staffing and patient outcomes demonstrate how increased $\mathrm{RN}$ staffing is associated with lower inpatient mortality and adverse patient events, including failure to rescue, cardiac arrest, and unplanned extubation (Kane, Shamliyan, Mueller, Duval, \& Wilt, 2007; Lang, Hodge, Olson, Romano, \& Kravitz, 2004), as well as shortened length of hospital stay (Lang et al., 2004). Given the relationship between increased numbers of baccalaureate-prepared nurses and improved patient outcomes, nurse leaders and educators in Canada worked to ensure that all nurses were prepared at the baccalaureate level for practice entry. This change was accomplished gradually through the closure of diploma programs and by establishing collaborative arrangements with baccalaureate programs (Wood, 2011).

\section{Reintroducing Nurse Diploma Education}

Despite disciplinary goals for baccalaureate education for entry into nursing practice, legislative changes in one western province reintroduced the diploma nurse category under regulatory reform initiatives (Health Professions Council, 2001; Province of British Columbia, 2016d). Practical nurse curricula subsequently expanded in in the province (from a one-year certificate to a two-year diploma), in parallel with shifting scopes of practice and expanding roles for LPNs (Johansen \& Styles, 2011; MacKinnon et al., 2018). The Practical Nursing Education Project (funded by the Ministry of Advanced Education) focused on aligning practical nurse education with the changing competencies and expanded scope of practice as outlined by the College of Practical Nurses for province (Johansen \& Styles, 2011).

A critical analysis of PN education in Canada (Butcher \& MacKinnon, 2015) revealed continued hierarchies and siloed nursing educational programs; lack of collaboration among professional, educational, and regulatory groups; inconsistent understandings of whether nursing was one profession (or two or more); and shifting scopes of practice framed as "differences in technical skills and not as differences in disciplinary knowledge or clinical reasoning" (p. 8). Further, skilled worker discourses and employer needs have also helped to sustain diploma nurse preparation (now situated as practical nursing). Questions arose as to how the practical nursing curriculum was being expanded in relation to the discipline of nursing. How was practical nurse education situated in relationship to nursing disciplinary knowledge? And how were legislative and educational shifts impacting how nurses learn to work together?

\section{Purpose}

The purpose of this research was to utilize an institutional ethnographic (IE) lens to reveal how various institutional (regulatory, educational, union, governmental, or health authority) texts and resources organize baccalaureate $(\mathrm{RN})$ and diploma (vocational or practical) nurses' experiences of learning to practice on acute care teams. This analytic thread evolved from a larger research study that sought to explore RNs' and LPNs' day-to-day experiences of changing work relationships in acute care hospitals. From the standpoint of nurses, part one of this work (MacKinnon et al., 2018) explored changing work relationships and scopes of practice between RNs and LPNs within the context of nursing care delivery reform (Care Delivery Model Redesign (CDMR)). A second analytic thread (MacKinnon, Bruce, \& Butcher, 2015) explored how nurses were being hooked into interprofessional care coordination work to ensure that patients were discharged efficiently. These previous analytic foci provided an entry point into 
this current analysis (Butcher, 2017). For this study, intraprofessional referred to categories of nurses (RNs and LPNs) under one nursing disciplinary umbrella.

\section{Methods}

\section{IE as a Framework}

Institutional ethnography (Smith, 1987, 1990, 2005, 2006) was utilized as a lens for approaching RNs and LPNs in acute care, to explore their everyday work experiences. Dorothy Smith's approach begins in the material work of people, as researchers talk with individuals (such as RNs and LPNs) who are considered the experts of their experience. Beginning from the standpoint of front-line workers provides an entry-point into understanding how institutional priorities organize the everyday work of people. More specifically, in observations and interviews, researchers looked for ways in which textually mediated work processes (such as regulatory, governmental, health authority, and educational documents) and other conceptual resources influence nurses' understandings of nursing education and professional practice. Various texts and resources, activated in the everyday work of people (Campbell \& Gregor, 2008; Smith, 1990, 2005), "shape and coordinate people's doings" (Smith \& Turner, 2014, p. 5). An IE investigation traces the activation of textually mediated discourses and institutional work processes to show the "organization of power as the concerting of people's activities" (Smith, 1990 , p. 83). Smith's $(2005,2006)$ approach to recruitment and data collection and analysis is emergent as informants share their knowledge about their everyday work, suggesting lines of investigation that help to uncover the social organization of their experiences.

\section{Recruitment}

Ten RNs and 10 LPNs were recruited from two small community hospitals chosen by the health authority (MacKinnon et al., 2018). IE is not concerned with obtaining a representative sample with assumptions that findings can be generalized. In contrast, we focused on tracing how the participant's varied experiences were linked to discourse and organizational processesthus allowing us to map social relations (Smith, 1987, 2006). Sample size decisions were influenced by what was needed to show how textually mediated work processes operate in various work contexts.

\section{Data Collection}

Observations of nurses at work and in-depth interviews were conducted between September and November 2014. Limited observation included tours of the hospital sites and attendance at two interdisciplinary structured team report meetings on two different nursing units. Twenty interviews ranging from 60 to 90 minutes were conducted. Questions began with asking participants to describe a typical shift and their experiences working with other team members. Participants were asked to describe differences and similarities in RN and LPN practice, roles, and education, to reveal possible education-related concepts and textual resources that informed their work for this analysis. All interviews were conducted at each hospital site in a private room. All interviews were audio-recorded and transcribed verbatim.

Subsequent questions built upon the previous conversation and iteratively provided information and questions for further interviews. It is in this way that institutional talk can be identified and then traced, offering more insights into the selection of other potential participants who may be helpful in informing understanding of how things work in a local setting. Thus, 
interviews were emergent, and researchers used each conversation to "expand understanding of the terrain" (Smith, 2006, p. 33).

\section{Analytic Methods and Rigor}

This empirical project began in the everyday, embodied work of nurses as experts in their own experience, rather than from an abstract or theoretical position. Uniquely, IE does not generalize experience; rather, an IE analysis traces how varied experiences on the ground are abstracted, objectified, and generalized via various institutional texts and resources. In Smith's (2005, 2006) IE approach, the focus and rigor of the analytic work is in showing how nurses' work is socially organized, by linking the local, everyday practice of nurses into the generalizing, standardizing institutional processes that reach beyond the nurses' local context and yet organize their everyday experience. Thus, a critical stance to the literature is taken for informing the analysis with the intention of promoting awareness and possible change (Campbell \& Gregor, 2008).

Textual analysis is a highly iterative process of repeatedly listening to audio-recorded interviews, reading transcripts, reviewing relevant documents, writing field notes, creating maps, and writing on-going reflective notes. In this study, the authors iteratively reflected upon and discussed these various notes and documents throughout the research process while also reflexively acknowledging the interrelationships among their roles, participant data, and analysis. Overall, trustworthiness was established by cohering to the conceptual framework of Smith's IE approach. This process included beginning in the everyday experiences of nurses, prolonged engagement with data, on-going discussions among the authors (one of which is an experienced IE researcher), and making visible how institutional texts from afar were organizing how nurses were learning to work together (Rankin, 2017; Smith, 2006).

The researchers listened and read for traces of social organization as reflected in the nurses' comments to reveal how participants understood, differentiated, and learned to work with each other. Interviewers looked for those moments in the talk of various nurses that linked to forms, documents, texts, or concepts which were rooted elsewhere-outside of their direct experience-but that linked in some way to speaking about their educational experiences and their learning to work in collaborative teams. NVivo was utilized for data management to organize threads of educational talk that were evident in the interviews. Relevant documents identified from the nurses' talk were obtained and analyzed. These texts included educational, governmental, regulatory, union, and health authority documents.

\section{Ethical Considerations}

Ethics approval for the study was obtained from the health authority and the University. Informed consent was obtained from all participants who volunteered to participate, and they were free to withdraw at any time. This study was funded by a University Internal Research Grant.

\section{Context and Participants}

This research project involved participants $(n=20)$ working in two acute care hospitals in small communities in a western Canadian province (MacKinnon et al., 2015). Table 1 below summarizes participant demographic information. Each hospital serves a geographic area with a population of 40 000-50 000 people. Five RNs and five LPNs who had experience working on inpatient medical or surgical units were interviewed at each hospital. RN-LPN-HCA teams 
worked together on medical units; RN-LPN teams worked together on surgical units. Each hospital also had overflow units, which functioned as long-term or "holding" beds for stable patients who were awaiting transfer to a residential care bed in the community. These units were staffed primarily by LPNs.

Table 1

Nurse participant characteristics $(n=20)$

\begin{tabular}{|c|c|c|c|c|}
\hline SITE & Participants & $\begin{array}{c}\text { \# years employed as } \\
\text { RN/LPN }\end{array}$ & $\begin{array}{l}\text { \# years working at } \\
\text { current site }\end{array}$ & $\begin{array}{c}\text { \# years on current } \\
\text { unit }\end{array}$ \\
\hline Site A & \multirow[t]{4}{*}{ RN (5) } & $<5$ years $(2)$ & $<5$ years $(2)$ & $<5$ years $(3)$ \\
\hline Roles: & & $10-14$ years $(2)^{*}$ & $5-9$ years $(2)$ & $5-9$ years $(2)$ \\
\hline & & $15+$ years $(1)$ & $10-14$ years 1$)$ & \\
\hline \multirow{5}{*}{$\begin{array}{l}\text { Staff nurses } \\
\text { (10) }\end{array}$} & & & $15+$ years & \\
\hline & \multirow[t]{4}{*}{ LPN (5) } & $<5$ years $(1)$ & $<5$ years $(3)$ & $<5$ years $(2)$ \\
\hline & & 5-9 years (1) & $5-9$ years $(1)$ & $5-9$ years (1) \\
\hline & & $10-14$ years $(2)$ & $10-14$ years $(1)$ & $10-14$ years $(1)$ \\
\hline & & 15+ years $(1)$ & & 15+ years $(1)$ \\
\hline Site B & \multirow[t]{4}{*}{ RN (5) } & $<5$ years $(1)$ & $<5$ years $(1)$ & $<5$ years $(2)$ \\
\hline Roles: & & $5-9$ years $(1)$ & $5-9$ years $(1)$ & $5-9$ years $(1) * *$ \\
\hline \multirow{2}{*}{$\begin{array}{l}\text { Staff nurses } \\
(8)\end{array}$} & & $15+$ years $(3)$ & $10-14$ years $(1)$ & $10-14$ years $(1)$ \\
\hline & & & $15+$ years $(2)$ & $15+$ years $(1)$ \\
\hline Nurse & \multirow[t]{3}{*}{ LPN (5) } & $<5$ years $(1)$ & $<5$ years $(2)$ & $<5$ years $(3)$ \\
\hline \multirow[t]{2}{*}{ Leaders (2) } & & $5-9$ years 2) & $5-9$ years $(2)$ & $5-9$ years $(1)$ \\
\hline & & $15+$ years $(2)$ & $15+$ years $(1)$ & $15+$ years $(1)$ \\
\hline
\end{tabular}

* RN who previously worked as an LPN included in $\mathrm{RN}$ group

**currently completing RN

\section{Learning to Work on Functionally Orientated Nursing Teams}

Both groups of nurses (LPNs and RNs) stated that they did not have an opportunity to work with other categories of nurses in their pre-registration education programs. Reflecting on her pre-licensure educational experiences, one RN noted:

Even as an RN coming in, I think that it comes down to a lack of knowledge as to what LPNs do and what RNs do because I was really naive when I got in here to the hospital about what LPNs did.

LPNs also reiterated that RNs did not often understand their roles or scopes of practice, nor did LPNs always understand unregulated health care aide (HCA) roles. One LPN participant stated: 
I really feel that a lot of RNs don't know LPNs scope of practice but, as an LPN, I don't fully understand the [HCAs] scope of practice. That's not something that we're taught in school, right... Yeah there are a lot of RNs that don't understand the LPN's scope of practice.

Both groups described differences in their practice as differences in what each category of nurse was "allowed to do", with a focus on tasks and skills:

They [RNs] do the IV meds. They do a lot of the blood, we don't hang the blood, they do a bit more of the consents for surgery, that kind of stuff, prepping... pulling out drains; they do flush-drains; they do more: like any wounds that have undermining or need wound vacs. (LPN participant)

In addition, the discourse of "stable and predictable" was used by LPNs to identify situations where a transfer to an RN was required (MacKinnon, Butcher, \& Bruce, 2018). Notably, there were also tensions as to whether body work or personal care was nursing care, and whether RNs, LPNs, or both learned this care as part of their education. This finding is analyzed further in another paper (MacKinnon et al., 2018).

Nurses in our study noted how those who had graduated under the previous, shorter (51 week) LPN curriculum were offered additional training; however, some of the older LPNs were hesitant to learn new skills or responsibilities: "the LPNs that had worked for 20 plus years on the floor were very reluctant to be more responsible, they just wanted to do those tasky things" (RN participant). This additional training was focused on developing the full scope of LPN practice, as hiring expectations (as noted in job descriptions for LPNs) required full scope practice.

Both groups of nurses struggled in their attempts to make sense of similarities and differences in their work that resulted in their different patient care assignments. Frequently mentioned was the obvious difference in the length of their educational programs (one or two years vs. four):

Well definitely the difference [in education] would be the length of time. RNs go to school for four years. LPNs, at one point, were only one year and have now expanded to two years and then the in-depth knowledge that RNs have [with] regards to pathophysiology and the rationale behind. What I find is that LPNs just sort of have the superficial understanding but when it comes down to, I don't know, like I guess the depth of knowledge, the RNs just have a deeper pool because they've gone to school for so much longer and similarities-wise, like again the basics. Not the basics but the foundations of nursing, so the critical thinking, the sterile technique and carrying out a safe nursing practice in general. (RN participant)

They [RNs] have three more years than me. When I took the [LPN] program it was one year, it was packed one year... with the body systems and everything. They [RNs] go a lot more in-depth. Yeah, three years, three years more education, that's why they're in charge. (LPN participant)

The depth of the knowledge base for RNs (with a longer educational program) was not framed as disciplinary knowledge, but reflected as biomedical knowledge nurses draw upon in acute care situations. Learning to think like a nurse-particularly complex thinking and clinical reasoning skills - was affected by the length of educational programming. However, both RNs 
and LPNs were expected to be "job ready" upon graduating from their programs. Organizational expectations to assist with new graduate transitioning or support for on-going educational opportunities (beyond occasional in-services regarding new equipment or treatments) were found to be very limited. Thus, it is within the context of pre-licensure educational silos (preventing each category of nursing student from learning about the other), struggles to define roles beyond tasks or skills, and expectations to be job-ready that we revealed the following findings of how RNs and LPNs are being socially organized to work together.

\section{Findings}

Beginning with participants' quotes, textual and conceptual resources that nurses drew upon in their talk were identified to reveal the social organization of their experience. As Smith (1990) suggests, these texts can be traced upwards to various documents (such as regulatory, governmental, health authority, or educational) that serve to discursively objectify experience across contexts and obscure the nurse's embodied, actual, and local experience (Smith, 1990). These authoritative, boss texts (Bisaillon, 2012; Griffith \& Smith, 2014) are hierarchically situated: serving to organize how nurses work across various contexts and subordinating bodily knowing to text-based knowing (Campbell, 1998).

The social organization of nurses' understandings of their work was revealed in talk about functional nursing roles and expectations for being practice-ready (to perform various skills and tasks). In addition, the absence of talk of the specialty status of acute care nursing encouraged worker flexibility as nurses (especially new graduates) were expected to float to various nursing units. Talk of how nurses learned and developed professional practice remained unarticulated. Nurses struggled to express how educational differences translated into knowledge or thinking differences. Significantly, there were no conversations of the nursing knowledge required to do their work. Each of these findings is explored in detail below.

\section{The Functional Nurse}

Nurses' talk centered on the functional roles of each category of nurse, that is, what each nurse would be doing. This functional care orientation channeled each nurse's focus, with RNs focused on care coordination roles (in addition to caring for the most ill patients), LPNs focused on task performance, and HCAs focused on tasks and communicating changes in patient status to nurses, as traced to a health authority care model document (Island Health, 2014):

The Patient Care Model is a collaborative team approach to providing patient care. It creates teams of Registered Nurses working with Licensed Practical Nurses and Health Care Assistants (care aides) to provide the right type of care to patients at the right time by the most appropriate caregiver...

RNs will provide a care coordination function within collaborative and interprofessional teams as they have been educated to do in their basic education. RNs carry out patient assessment and care planning, deliver patient education and discuss care goals and the plan for a return home with patients and their families...

LPNs can care for patients who have a written plan of care that outlines what tasks are required to support their return or stabilization of health. The assignment of patients to LPNs... includes decision making around what are the care needs of individual patients, what care provider has the knowledge and competencies to safely provide this care, and an understanding of all employer determined policies and 
guidelines around specific tasks and activities that patients may require. LPNs working on units that have undergone the implementation of the Patient Care Model will provide care in a team nursing approach...

HCAs will work as part of a collaborative nursing team. This process includes receiving instructions and assignments from other members of the care team (LPNs and RNs or other professional staff), gathering information on patient's unique needs from care plans, participating in standard communication practices, and reporting abnormal or unexpected behaviours that they observe. HCAs are educated to assist patients with mobility, self-care, toileting, and hydration/eating (Care Model Implementation FAQs sheet, health authority).

Nurses' work was organized in ways that supported the functional roles as noted above. Nurses describe how roles have changed since the introduction of health care aides and how RN work is organized to take them further from the bedside:

I think the LPNs are knowledgeable. I think that... unpredictable patients are something we all need to be aware of. I think LPNs are very good, they spend a lot more time with the patient doing the dressings, those kinds of things. A good LPN is doing a really good assessment while they're getting somebody washed, while they're getting them up in the morning. That doesn't mean an RN can't, shouldn't be able to do that, too, but the RN's role is moving... [seemingly] away from the actual touching of and the bedside of the patient to developing the care plan and doing the med reconciliation... (RN participant)

[A] care aide works with the nurse from [one team] primarily in the morning and takes care of the patient care, so washes the patients up. And then when all those four patients are done then the care aide expands out to the rest of the floor and the care aide basically just goes around, and in the morning the care aide gets report with us so finds out, you know, who's a one person, two person, overhead lift and such, and then they just kind of seem to go around and do their thing... you go in to wash a patient up and the care aide's already done it. They just kind of float like butterflies and do their thing. (LPN participant)

Several of the nurses were also in float positions (or had been as new graduates) that required them to be flexible in adjusting to unit-specific team orientations, which varied depending on the needs of each unit.

\section{Absence of Talk about Nursing-specific Knowledge}

This finding was not surprising, considering the reorganization of nursing practice as noted above. In the interviews, we asked nurses to articulate similarities and differences in their educational experiences and in their work, roles, and practice. Here, nurses often had more difficulty choosing words to describe their experiences. When asked about differences in the work of RNs and LPNs, an LPN participant responded:

Critically thinking I think that... they [RNs] do have more of a background with that kind of — not really critical thinking — more, more, what's the word I'm looking for... just like a deeper background as to different health concerns or whatever it is... they get more education and pathology classes and they go to school for longer so they should.

This LPN mentions the words critical thinking, a term that is well-utilized by educators, students, and nurses alike, to describe the thinking work that they learn to do and practice as 
nurses. This nurse struggles to find a word or phrase that would be a better fit than critical thinking for describing the thinking differences between RNs and LPNs.

The critical thinking that nursing students learn and practice, while not fully articulated, becomes a significant difference when it comes to which patients for each group of nurse cares, with the more unstable or acutely ill patients being assigned to RNs. An LPN (currently completing her BSN degree) goes on to describe this difference:

The LPN [program] I found to be a very condensed crash course [laughs] that prepared me to deal with stable patients with predictable outcomes-that means limited intervention in an acute care setting. When I went to be an RN, I spent a lot more time, my education is so much more in-depth because I learned everything, and I now have the ability to intervene and make decisions in patients whose status is changing rather quickly on me.

The silent discourse of nursing knowledge was subsumed under not fully articulated differences in critical thinking, in-depth knowledge, length of education, and pathophysiology: areas with which nurses struggle as they do not seem to capture what they learn to do as nurses.

\section{Being Practice-ready (Skills/Task Proficient)}

There were also expectations that differences in the education of RNs and LPNs meant that RNs come into practice "already knowing everything", or that all graduates are practice ready, which contrasts with how professional development unfolds and the needs of new graduate nurses:

We [LPNs] don't necessarily know everything when we first come out of school. We don't have as much background as they [RNs] do. And really, they [RNs] take the really acute patients so that's their role on the floor. We take patients you know that aren't acute anymore and that's the big difference and of course if you're working in Emerg. or ICU or something like that, that's where you see a huge difference in tasks. (LPN participant)

In contrast to being practice ready, some of the nurses talked about the significant stresses when transitioning to practice as new graduates. For one LPN, this meant attempting to focus on remaining calm to effectively do her work:

I've had to learn to be able to prioritize and to always try to remain calm because when I was first nursing I just remember I would feel overwhelmed and panicky and I wanted to do everything and that's a quick trip to insanity-land. (LPN participant)

What was disturbing was how the amount of overwhelming stress for a new RN graduate created a wish to have a minor car crash to avoid coming to work and facing her challenging work environment:

I've talked to a lot of new grads and I'd just like to tell them that it's very hard and it's stressful and you're just kind of going through the motions for quite a while. At least six months that you're kind of, you're driving to work and you just kind of pray that you get in a mini fender-bender so you don't have to go to work that day. So, you're not hurt but rear-ended. Just enough, right? And that's what is true. That's exactly what it's like. And it is hard and it is challenging. (RN participant)

An experienced LPN participant, currently completing her RN degree, noted how she would expect on-going support learning her new role and responsibilities as an RN: 
I am expecting that [support]. I anticipate that. I can see how it would be very frustrating if I don't have that and I wouldn't be very happy, so I hope to have that... you should have lots of support when you're a new grad because there's a lot that you don't know.

Some graduate nurses did have transition support through the health authority (New Graduate Transition Program), where nurses obtain full-time hours on one unit for one year, in addition to having a mentor. However, due to chronic staff shortages, the mentor could not always be assigned as an extra staff member, which impeded ongoing learning support for the new graduate and created significant stress:

I started in a new grad full-time job... the new grad transition program, so I had full-time work for a year on one unit... I had a mentor-we went to classes together before I even started working. We had a whole weekend workshop. We had that put on by [the health authority] and then I had a number of shifts with her and then she was extra. But as it stands, not always extra because that's life—we're always short—somebody's always calling in sick... vacation... So that's what I came out of and I'm still traumatized from my first year of nursing. I remember it very, very clearly and how hard it was and my husband told me that the spirit had been sucked out of me about eight months into nursing. (RN participant)

Importantly, both RNs and LPNs described significant challenges (and differing responsibilities) as they transitioned into to the work environment. It was noted how discourses of scope, tasks, and skills were orienting nurses to describe their work in divisive and categorical ways, while less prevalent were discussions regarding differences in knowledge or thinking skills between RNs and LPNs. Ultimately, there were organizational expectations that both groups of nurses be "finished products" at graduation, be job-ready to step into work, and perform necessary tasks and skills. This expectation also negates the necessity of workplaces to provide on-going professional development to support nurses in multi-specialist acute care areas.

Responsibilities related to the above-categorized roles did not allow for new graduate transition support for new nurses and created significant stress for new graduates as they were expected to immediately accept significant responsibility in their designated roles. RNs' expanded scope of practice was being increasingly focused on administrative work, as analyzed in another article (MacKinnon et al., 2018). Learning about and trusting each other was also impeded by new graduates being hired in float or casual positions, which prevented them from establishing relationships (and gaining confidence) with a unit or team (however, provided employer-sanctioned interchangeable workers).

\section{The Non-specialist, Flexible Worker}

Another unarticulated or silent discourse relates to the specialist, generalist-specialist, or multi-specialist nature of medical-surgical nursing work. Although not identified by nurses in the study as multi-specialist knowledge, the nurses talked about needing knowledge of multiple areas that could be situated among specialty practice domains, such as cardiovascular, medicalsurgical, gerontological, psychiatric/mental health and hospice/palliative care. One RN, in discussing a typical day on her medical unit, outlined how she had "cared for one palliative patient who passed", admitted a patient who was a "transfer from the surgical end [who's] 19day post-op with acute chest pains", and patients admitted with dementia where "they can't give you the information so you have to wait for the family or phone the family to try to dig [for] information." 
There are currently 20 certifications offered to nurses as part of professional development, including a medical-surgical certification (Canadian Nurses Association, 2017). Interestingly, none of the nurses we interviewed talked about these courses, identified their practice as a specialty, or how the knowledge needed for their practice intersected with numerous specialty strands. There were noted tensions around baccalaureate education and preparing students for specialty areas, which assumed exclusion of medical-surgical areas. One $\mathrm{RN}$, reflecting on changes in the baccalaureate program where third-year students can begin specialty courses, notes her concerns:

I worked with a third-year student down on [medical unit], I was pulled down there one night and I worked with [her]-she's already starting her OR courses-because she wasn't going to work on the wards. I feel like that's what they're gearing the nursing program towards: more theory, more paperwork, more care planning, more specialty practice. Which is all good and fine but you still need RNs, in my opinion you still need RNs here. I couldn't do with any less RNs. Sometimes they pull an RN and fill it with an LPN. It happens more on nights than days. I start to panic. I'm like, we have 22 patients. I have five already. If one of these LPN patients is going sour or heaven forbid, more than one, I'm going to be taking those patients on.

There are concerns about the significant increasing responsibilities for RNs who must accept care for increasingly unstable patients who are not appropriate to be cared for by LPNs. By focusing RNs on specialty practice during pre-licensure education, there will be fewer RNs available to work on general acute care units where they are very much needed. However, socially organizing medical-surgical nurses as non-specialty provides an additional means for producing flexible nurses. This viewpoint raises questions as to how specialty nursing knowledge is defined (and by whom: nurses, physicians, or employers), and how specialty nursing education might be positioned for nurses in the future. Within practice contexts which fail to address the need for professional support and development, these findings of functional nurse talk, unarticulated nursing knowledge, practice-readiness, and nurse manageability/flexibility create concerns and challenges for nursing education.

\section{Discussion}

\section{Nurse Flexibility and Neglect of Professional Development-Implications for Education}

The social organization of nurses learning to work together in the workplace occurs via textually mediated practices that sustain nurse categorization, interchangeability, role ambiguity, and expectations for job readiness. Textually mediated shifts towards functionally orientated nursing teams (with a focus on tasks and skills) and flexible workers (manageable employees) create significant implications for nursing education. RNs and LPNs did not specifically talk about nursing knowledge or higher-level thinking skills. Since the knowledge required for professional practice (such as relational inquiry, clinical reasoning, and advanced nursing assessment) remains unarticulated, demarcation among nurse categories is instead sustained via task, role, and skill division talk. Workplace documents (such as job descriptions for RNs and LPNs) were less apt to describe nursing as requiring nursing knowledge. Rather, job descriptions list skills, tasks, duties, and responsibilities for nurses within functional contexts:

The RN provides nursing care by performing nursing functions such as: direct nursing care to patients, explaining care plan to patient and family; conducting planned nursing 
interventions; initiating measures to relieve emergent situations; and teaching self/home care skills to patients and/or family members (Island Health, 2016).

While nurse participants acknowledged educational and knowledge differences between RNs and LPNs (framed as hesitant talk about critical thinking or biomedical knowledge), nurses had difficulty fully articulating those differences. Devault (1990) notes the significance for IE work in noticing the "halting, hesitant, tentative talk" (p. 103) that characterizes a search for words to describe often-unacknowledged experiences. Here, Devault argues, people often resort to using institutional concepts, which often do not completely fit what the person wants to say.

Further, unrecognized nursing knowledge leaves the door open to textually mediate "sameness" among nurses, as well as in skilled worker, care model, efficiency, interprofessional, and safety conversations, which realign nurses' work and suggest interchangeability of nurses (Thorne, 2014, 2015). Our finding of this silent discourse echoes Voldbjerg, Grenkjǽr, Wiechula, and Serensen (2017), who completed an ethnographic analysis of knowledge sources utilized by new BSN graduates. These authors found that "using knowledge from undergraduate education was mostly covert, difficult to locate through observations and challenging for the informants to articulate" (p. 1321). This finding suggests that the inability to articulate nursing knowledge may indicate that it is "seldom articulated and questioned" (Voldbjerg et al., 2017, p. 1323).

Neglect of professional development. Significantly, this finding also raises questions as to whether assessments of nursing knowledge or professional development are included in certain research approaches used to justify shifts toward functional care models. Analytic models that only track observable tasks performed appear to disregard underlying knowledge required to do nursing work (Joyce, McLaren, \& Tully, 2010; Stevenson, Parent, \& Purkis, 2012; White et al., 2009). While some student nurses may be learning what professional practice entails, it is not supported within workplace contexts. Notably, evidence related to patient safety and baccalaureate-prepared RN staffing ratios and increased nurse satisfaction in professional practice models remains silent, which raises questions as to whose voices are being heard (and whose are being silenced) in care model conversations.

Interestingly, both RNs and LPNs are expected to enter the workplace fully ready to perform their roles; however, their roles are significantly impacted by workplace conceptualizations of these roles. Educational programs for each nursing category are siloed with varied requirements for admission (Appendix A), which significantly limits opportunities for professional career growth (and higher salaries), sustaining nurses on narrow paths within the "pink collar ghetto" (Bernhagen \& Gravett, 2017; Brown, 1995). Pink-collar workers are in jobs traditionally occupied by women; jobs characterized by low wages, lack of career path, little hope for career advancement (Kleiman, 2006), and are "highly monitored with little authority to make decisions" (Hulme, 2006, p. 145). For example, LPN programs are frequently "dead end" programs, as many do not offer ongoing professional development. While educational programming for LPNs explicitly supports practice-readiness, baccalaureate programming recognizes the significance of practice transitioning and development of professional competence (Appendix A).

While there are assumptions that a professional nursing practice model is desirable (such as in educational, union, and regulatory documents), nurses' work on the ground is organized very differently, as revealed in our research. Upon entering the workplace, both groups of nurses 
actively engage with and enact the institutional discourses of task and skill delineation that serve to override the professional practice orientation of $\mathrm{RN}$ education, simultaneously reinforcing the task orientation of LPN practice. The nurses' union (of which both RNs and LPNs are members) acknowledges how nursing "has its own educational programs and generates its own body of research that supports nursing excellence" (British Columbia Nurses' Union [BCNU], 2015b, p. 3 ). However, union support of blurred nursing categories and siloed education is counterintuitive to much of nursing's disciplinary evidence. How might educators within RN and LPN programs reconcile expectations for teaching professional practice with job-readiness? And, in what contexts (such as acute care or community health) are employers' needs for these workers most urgent?

Tracing textual and conceptual resources from nurses' talk revealed how, at the highest levels (the boss texts as outlined in Appendix B), RN and LPNs scopes are significantly blurred, which suggests that there are assumptions that little differentiation exists between RNs and LPNs. Nursing union documents frequently refer to nurses, the nursing family, or the nursing profession, leaving RN or LPN categories undifferentiated (BCNU, 2015a, 2015b). Definitions of RN and LPN scopes of practice in a legislative document (Health Professions Council, 2001) are significantly blurred, except for one added statement for RNs regarding care coordination:

Scope of Practice for LPN: "provision of health care for the promotion, maintenance, and restoration of health; and the prevention, treatment, \& palliation of illness and injury, including assessment of health status and implementation of interventions" (p. 17)

Scope of Practice for RN: "provision of health care for the promotion, maintenance, and restoration of health; the prevention, treatment, \& palliation of illness and injury, primarily by assessment of health status and implementation of interventions; and coordination of health services" (p. 18)

Further, blurring of regulatory boundaries as part of regulatory reform (Health Professions Council, 2001), including creating restricted activities (tasks formerly known as reserved acts), suggests that tasks are easily transferable between professions and unregulated providers. This approach does not attend to the cognitive elements rooted in disciplinary knowledge and practices that inform the performance of a task during patient care. Ultimately, these shifts assist health care institutions in utilizing workers in flexible ways.

Functional orientations towards nursing care help sustain nurse categories and "view nursing as a broad set of tasks that can be done by a variety of workers, and the focus of health care organizations is to subdivide work among many workers, use them flexibly, and control their activities" (Dubois et al., 2012, p. 11). These models utilize LPNs and other health care workers in response to economic and labour constraints, and they focus on managing nursing resources in a flexible way (Dubois et al., 2012). Further, functional approaches to nursing care undermine the development of professional practice and perpetuate ambiguity, as nurses struggle to delineate difference in their roles (Dubois et al., 2012).

Disruption of development of competence. The notion of less complex and stable patients being cared for by LPNs, while RNs are fully responsible for the most complex and ill, somewhat mirrors novice-to-expert and new graduate transition theorizing, but with a unique twist. The development of competent practice is disrupted by institutional expectations of jobreadiness, and counterintuitive narrowing of $\mathrm{RN}$ scopes (with a focus on care co-ordination) with simultaneous widening of LPN scopes (with a focus on skills and tasks). Influenced by cost- 
saving, "lean" approaches to health care administration (Joosten et al., 2009; Kitson, Athlin, \& Conroy, 2014; Rankin \& Campbell, 2006), the complexities of nursing practice become standardized and simplified, and "this reduced complexity might make it possible for these jobs to be executed by less highly trained professionals" (Joosten et al., 2009, p. 343). Consequently, this shift reorients nursing professionals to focus on only the most complex patients. The negotiating and renegotiating work of patient assignments (related to acuity and complexity) is discussed in detail in another paper (MacKinnon et al., 2018).

Registered nurses develop professional competence (along the novice-to-expert continuum) by supportive workplace environments that allow for nurse leaders to consider each nurse's ability to care for patients of varying complexity. This professional practice orientation is acknowledged in the Canadian Council of Registered Nurse Regulators (CCRNR) 2012 document outlining the significance of a supportive workplace for new BSN graduate practice and role acquisition (however, it is not noted in the Canadian Council of Practical Nurse Regulators (CCPNR) document for LPNs):

Research demonstrates that during the first 12 months of employment, entry-level registered nurses experience a complex but relatively predicable array of emotional, intellectual, physical, sociocultural, and developmental issues... role acquisition occurs in part by observing other registered nurses in practice and within the social network of their workplace. Time is required to establish professional relationships, learn practice norms, and consolidate nursing practice knowledge and judgment. As confidence develops in their new role, entry-level registered nurses assume higher levels of responsibility and manage increasingly complex clinical situations. Their proficiency and efficiency with respect to workload management and technical skills will improve with support and experience. (p. 6)

There remain questions as to whether findings from research examining $\mathrm{RN}$ role acquisition are applicable in LPN educational or practice contexts. Further, none of the nurses in our study mentioned the significance of educators' calls for the baccalaureate degree as entry into nursing practice. New nurses are also currently under significant stress as they are expected to immediately function as if they are experienced nurses. Further, the added burden of acting as mentors for students added significant stress and workload. Questions thus arise, and further research is warranted to investigate how practice-readiness expectations (and expectations for RNs to be team leaders and discharge planners) interfere with the development of competent and expert practice (MacKinnon et al., 2018). Interestingly, Goode, Ponte, and Havens (2016) have created policy recommendations for supporting practice transition and professional development for new RN graduates. They recommend that: 1) hospitals and schools of nursing collaborate to develop nurse residency programs (NRP) for all baccalaureate and diploma (RN-associate degree) graduates working in acute care; 2) completion of a NRP should be a condition of hire for new nurses; 3) all NRP should be nationally accredited; 4) nursing accrediting bodies should require entry-level nursing programs (degree and diploma) to assist in development and administration of NRP; and 5) hospitals that hire diploma ( $\mathrm{RN}$-associate degree) nurses should require that a baccalaureate degree be completed within a certain timeframe to maintain employment.

Limoges and Jagos (2015), in their exploration of intraprofessional learning experiences among RN and PN students, noted how both groups of students engaged in "sameness talk, suggesting that there was no real difference between the [LPN] and RN except for the amount of 
money they made for the same work" (p. 1026). This sameness talk suggests that student nurses are not understanding the knowledge differences that are supported with longer RN programs and reveals students' active participation in interchangeability discourses, which undermines their own professional development. Sameness talk may also be a response to limited career mobility or lack of access to various nursing programming. What is most fascinating and troubling is that nurses on the ground are calling for increasing role clarity and delineation, while the grand scheme at various institutional levels is to purposefully blur lines of demarcation to facilitate efficient, interchangeable, and more sustainable (economical) nurses.

\section{Conclusion}

The findings of our study cannot be generalized, as our participants' experiences were embedded in a specific context, and participants were recruited in a purposive manner. Rather, it is the goal of IE work to reveal the generalizing effects of texts that reorganize how nurses learn to work together to fulfill organizational objectives. Transferability of the findings to other contexts will need to be determined by readers of this research. However, IE provides an entry point into understanding how the everyday work of nurses is textually coordinated across time and space. The texts and conceptual resources that are well beyond nurses' local work context, and yet have organizing and generalizing effects, may have relevance for readers in other contexts. This research is significant in offering a portal for further exploration of discourses and processes that organize educator, nurse, and health care aide work, both within and beyond acute care. Further, this research can assist in making nurses and educators more aware of the political nature of their work and how predominating discursive resources from afar impact their everyday work of nursing.

This analysis has focused on how RNs and LPNs learn to work on redesigned nursing teams and traces the textually mediated discourses that are organizing this learning in the context of recent changes to LPN education and nursing teams. Our findings highlight unarticulated nursing knowledge/thinking, and the textual insertion of functional, skilled and flexible worker discourses, which blur practice between RN and LPNs making them [potentially] interchangeable in complex acute care contexts. This study, situated as one analysis among others (MacKinnon et al., 2018) shows the invisibility of nursing disciplinary and professional goals and knowledge in nurses' talk, as RNs and LPNs relearn and sustain nursing practice in ways that fulfill other institutional and organizational goals.

This realignment has significant implications for educators in nursing programs, who participate in teaching within educational silos. This research has shown that the absence of clarity in functional roles (perpetuating role confusion and ambiguity) is purposeful, with the goal of creating flexible workers. This finding raises the question as to whether all facets of professional nursing practice are being attended to within clinical, regulatory, union, and academic organizations. Further, for the primary author, this IE work has provided insights into understandings of the chafing that occurred while teaching in practical nurse contexts. Disciplinary nursing goals, such as providing holistic care in relational contexts, are subsumed under nurses' talk of nursing practice as skills and tasks. In the workplace, nurses are organized to relearn nursing in simplified, stratified, and categorized ways, which disrupts the complexity and fluidity of professional (full-scope) nursing practice for not only LPNs, but RNs as well (MacKinnon et al., 2018). 
Interestingly, LPN-RN access or bridging programs are not currently available in our local context (Appendix B). Perhaps this too speaks to the assumptions of worker flexibility. It is intriguing that there is little talk in providing a transition from LPN to RN education (and from a practice-ready or functional model to a professional practice model of education), despite the provincial government listing registered nursing (specialty) and registered nursing (general) as number one and three respectively on their list of high-opportunity health professions in labour market outlook predictions (Province of British Columbia, 2016a).

Future research should examine how reintroducing nurses within functional roles might maintain traditional (inter- and intraprofessional) educational hierarchies and silos. How might functional, task-oriented care models within tightly regulated nursing categories interfere with the professional goals of our discipline? Since one goal of having the baccalaureate degree as entry to nursing practice was to "level the playing field" among various health care professionals, an IE analysis of the everyday work of interprofessional teams (RNs working with dieticians, occupational therapists, social workers, physicians, and physiotherapists, for example) would be fruitful in examining the experiences of interprofessional teams. Further research is also needed comparing the quality of private BSN and LPN college programs with governmentfunded programs. Nursing educators are often situated on the line of fault between professional nursing education and the realities of practice, and so this research offers a means for educators to see, reflect upon, and push back against the impact of institutional texts on not only teaching and learning, but how RNs and LPNs view each other and their practice. 


\section{References}

Aiken, L., Clarke, S., Cheung, R., Sloane, D., \& Silber, J. (2003). Educational levels of hospital nurses and surgical patient mortality. Journal of the American Medical Association, 290, 1617-1623. https://doi.org/10.1001/jama.290.12.1617

Aiken, L., Clarke, S., Sloane, D., Sochalski, J., \& Silber, J. (2002). Hospital nurse staffing and patient mortality, nurse burnout, and job dissatisfaction. Journal of the American Medical Association, 288, 1987-1993. https://doi.org/10.1001/jama.288.16.1987

Bernhagen, L., \& Gravett, E. (2017). Educational development as pink collar labor: Implications and recommendations. To Improve the Academy, 36, 9-19. https://doi.org/10.1002/tia2.20053

Bisaillon, L. (2012). An analytic glossary to social inquiry using institutional and political activist ethnography. International Journal of Qualitative Methods, 11(5), 607-627. https://doi.org/10.1177/160940691201100506

British Columbia Nurses' Union [BCNU]. (2015a). BCNU position statement: Mandated nurse patient ratios. Burnaby, BC: Author.

BCNU. (2015b). BCNU position statement: Nurse autonomy. Burnaby, BC: Author.

Brown, K. (1995). Out of the pink collar ghetto: Restructuring and equity. International Journal of Employment Studies, 3(2), 135-144.

Butcher, D. L. (2017). Walking on unstable ground: Registered nurses' and licensed practical nurses' experiences of learning to work together using a methodologically plural approach [Doctoral dissertation, University of Victoria, BC]. Retrieved from https://dspace.library.uvic.ca//handle/1828/8508

Butcher, D. L., \& MacKinnon, K. A. (2015). Educational silos in nursing education: A critical review of practical nurse education in Canada. Nursing Inquiry, 22(3), 231-239. https://doi.org/10.1111/nin.12090

Butcher, D. L., MacKinnon, K. A., Bruce, A., Gordon, C., \& Koning, C. (2017). The experiences of pre-licensure or pre-registration health professional students and their educators learning in working with intra-professional teams: A qualitative systematic review. JBI Database of Systematic Reviews and Implementation Reports, 15(4), 1-46. https://doi.org/10.11124/jbisrir-2016-003009

Campbell, M. L. (1998). Institutional ethnography and experience as data. Qualitative Sociology, 21(1), 55-73.

Campbell, M., \& Gregor, F. (2008). Mapping social relations: A primer in doing institutional ethnography. Toronto, ON: University of Toronto Press.

Canadian Council of Practical Nurse Regulators. (2013). Entry-to-practice competencies for licensed practical nurses. Burnaby, BC: Author. Retrieved from http://www.ccpnr.ca/wp-content/uploads/2013/09/IJLPN-ETPC-Final.pdf

Canadian Council of Registered Nurse Regulators. (2012). Competencies in the context of entrylevel registered nurse practice. Beaverton, ON: Author. Retrieved from http://www.ccrnr.ca/assets/jcp_rn_competencies_2012_edition.pdf 
Canadian Nurses Association. (2017). Certification nursing practice specialities. Ottawa, ON: Author. Retrieved from https://nurseone.ca/en/certification/get-certified/certificationnursing-practice-specialties

College of Registered Nurses of BC [CRNBC]. (2012). Underlying philosophies and trends affecting professional regulation. Vancouver, BC: Author.

Devault, M. J. (1990). Talking and listening from women's standpoint: Feminist strategies for interviewing and analysis. Social Problems, 37(1), 98-116.

https://doi.org/10.1525/sp.1990.37.1.03a00070

Dubois, C., D’Amour, D., Tchouaket, E., Rivard, M., Clarke, S., \& Blais, R. (2012). A taxonomy of nursing care organization models in hospitals. BMC Health Services Research, 12(286), 1-15. https://doi.org/10.1186/1472-6963-12-286

Fraser, J. (2011). Nursing professional practice: An evolutionary concept analysis. (Unpublished master's of nursing thesis). University of Victoria: Victoria, BC.

Goode, C. J., Ponte, P. R., \& Havens, D. S. (2016). Residency for transition to practice: An essential requirement for new graduates from basic RN programs. Journal of Nursing Administration, 46(2), 82-86. https://doi.org/10.1097/nna.0000000000000300

Griffith, A. I., \& Smith, D. E. (2014). Under new public management: Institutional ethnographies of changing front-line work. Toronto, ON: University of Toronto Press.

Health Professions Council. (2001). Safe choices: A new model for regulating health professions in British Columbia. Victoria, BC: Ministry of Health Planning. Retrieved from http://www2.gov.bc.ca/assets/gov/government/ministries-

organizations/ministries/health/safe-choices-a-new-model-for-regulating-healthprofessions-in-british-columbia.pdf

Hulme, K. (2006). Making the shift from pink collars to blue ones: Women's non-traditional occupations. Labour/La Travail, 57, 143-165.

Island Health. (2014). Frequently asked questions: Patient care model implementation. Victoria, BC: Author. Retrieved from http://www.viha.ca/NR/rdonlyres/D76D4748-3AC4-4EE4A8D2-37C7FFDC8B9C/0/FSpatientcaremodel_faq.pdf

Island Health (2016). Careers: Public Postings. Victoria, BC: Island Health. Retrieved from https://viha.hua.hrsmart.com/ats/job_search.php

Johansen, S., \& Styles, L. (2011). Practical nursing program provincial curriculum. Burnaby, BC: Academic Health Council. Retrieved from https://pn.bccampus.ca/pluginfile.php/884/mod_resource/content/1/Practical\%20Nursing \%20Program\%20Provincial\%20Curriculum.pdf

Joosten, T., Bongers, I., \& Janssen, R. (2009). Application of lean thinking to health care: Issues and observations. International Journal for Quality in Health Care, 21(5), 341-347. https://doi.org/10.1093/intqhc/mzp036

Joyce, S., MacLaren, J., \& Tully, J. (2010). Care delivery model redesign (CDMR). Victoria, BC: Island Health, Fraser Health Authority, \& Government of British Columbia. 
Kane, R., Shamliyan, T., Mueller, C., Duval, S., \& Wilt, T. (2007). Staffing levels and patient outcomes: Systematic review and meta-analysis. Medical Care, 45(12), 1195-1204.

Kitson, A. L., Athlin, A. M., \& Conroy, T. (2014). Anything but basic: Nursing's challenge in meeting patients' fundamental care needs. Journal of Nursing Scholarship, 46(5), 331339. https://doi.org/10.1111/jnu.12081

Kleiman, C. (2006, January 8). Pink-collar workers fight to leave "ghetto". Seattle Times, Retrieved from http://www.seattletimes.com

Lang, T. A., Hodge, M., Olson, V., Romano, P. S., \& Kravitz, R. L. (2004). Nurse-patient ratios: A systematic review on the effects of nurse staffing on patient, nurse employee, and hospital outcomes. Journal of Nursing Administration, 34(7/8), 326-337. https://doi.org/10.1097/00005110-200407000-00005

Lankshear, A., Sheldon, T., \& Maynard, A. (2005). Nurse staffing and healthcare outcomes: A systematic review of the international research evidence. Advances in Nursing Science 28, 163-174. https://doi.org/10.1097/00012272-200504000-00008

Limoges, J., \& Jagos, K. (2015). The influences on nursing education on the socialization and professional working relationships of Canadian practical and degree nursing students: A critical analysis. Nurse Education Today, 35, 1023-1027. https://doi.org/10.1016/j.nedt.2015.07.018

MacKinnon, K., Bruce, A., \& Butcher, D. (2015, June). Re-designing nurses' work: How institutional work practices perpetuate health inequities in small community hospitals. Paper presented at the ISIH International Conference: Challenging Health Inequity: A Call to Action, Palma de Mallorca, Spain.

MacKinnon, K. A., Butcher, D. L., \& Bruce, A. (2018). Working to full scope: The reorganization of nursing work in two Canadian community hospitals. Global Qualitative Nursing Research, 5, 1-14. https://doi.org/10.1177/2333393617753905

McGillis Hall, L., Doran, D., \& Pink, G. (2004). Nurse staffing models, nursing hours, and patient safety outcomes. The Journal of Nursing Administration, 34, 41-45. https://doi.org/10.1097/00005110-200401000-00009

Province of British Columbia. (2016a). British Columbia 2025: Labour market outlook. Victoria, BC: Government of BC. Retrieved from https://www.workbc.ca/getmedia/00de3b150551-4f70-9e6b-23ffb6c9cb86/LabourMarketOutlook.pdf.aspx

Province of British Columbia, (2016b). Health care aide oversight: Policy intentions paper for consultation. Victoria, BC: Government of BC. Retrieved from http://www2.gov.bc.ca/assets/gov/health/practitioner-pro/professionalregulation/hca_new.pdf

Province of British Columbia. (2016c). Scope of practice reform. Victoria, BC: Government of BC. Retrieved from http://www2.gov.bc.ca/gov/content/health/practitioner-professionalresources/professional-regulation/scope-of-practice-reform

Province of British Columbia. (2016d). Health professions act. Victoria, BC: Government of BC. Retrieved from http://www.bclaws.ca/EPLibraries/bclaws_new/document/ID/freeside/00_96183_01 
Rankin, J. M. (2017). Conducting analysis in insitutional ethnography: Guidance and cautions. International Journal of Qualitative Methods, 16, 1-11. https://doi.org/10.1177/1609406917734472

Rankin, J. M., \& Campbell, M. L. (2006). Managing to nurse: Inside Canada's health care reform. Toronto, ON: University of Toronto Press.

Smith, D. E. (1987). The everyday world as problematic: A feminist sociology. Boston, MA: Northeastern University Press.

Smith, D. E. (1990). The conceptual practices of power: A feminist sociology of knowledge. Toronto, ON: University of Toronto Press.

Smith, D. E. (2005). Institutional ethnography: A sociology for people. New York, NY: Roman \& Littlefield.

Smith, D. E. (2006). Institutional ethnography as practice. New York, NY: Roman \& Littlefield.

Smith, D. E., \& Turner, S. M. (2014). Incorporating texts into institutional ethnographies. Toronto, ON: University of Toronto Press.

Stevenson, L., Parent, K., \& Purkis, M. (2012). Redesigning care delivery in British Columbia. Healthcare Management Forum, 25(1), 16-19. https://doi.org/10.1016/j.hcmf.2011.09.009

Thorne, S. (2014). What constitutes core disciplinary knowledge? Nursing Inquiry, 21(1), 1-2. https://doi.org/10.1111/nin.12062

Thorne, S. (2015). Does nursing represent a unique angle of vision? If so, what is it? Nursing Inquiry, 22(4), 283-284. https://doi.org/10.1111/nin.12128

Voldbjerg, S. L., Grenkjǽr, M., Wiechula, R., \& Sөrensen, E. E. (2017). Newly graduated nurses' use of knowledge sources in clinical decision-making: An ethnographic study. Journal of Clinical Nursing, 26, 1313-1327. https://doi.org/10.1111/jocn.13628

White, D., Jackson, K., Besner, J., Suter, E., Doran, D., McGillis Hall, L., \& Parent, K. (2009). Enhancing nursing role effectiveness through job redesign. Calgary, AB: Alberta Health Services.

Wood, M. J. (2011). Entry to practice: Striving for the baccalaureate standard. In J. C. Ross-Kerr \& M. J. Wood (Eds.), Canadian nursing: Issues \& Perspectives (5th ed., pp. 359-373). Toronto, ON: Elsevier.

World Health Organization [WHO]. (2008). Task shifting: Rational redistribution of tasks among health workforce teams. Geneva, Switzerland: Author. 
Quality Advancement in Nursing Education - Avancées en formation infirmière, Vol. 4, Iss. 1 [2018], Art. 2

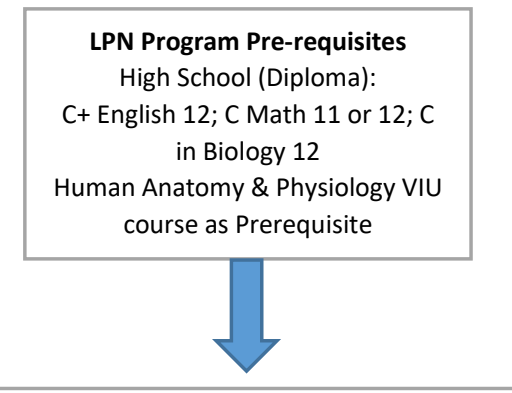

About the PRACTICAL NURSE Program

2 year diploma program prepares graduates to provide nursing care in a diverse range of employment settings including:

hospitals, nursing homes, extended care facilities, rehabilitation centres, doctors' offices, clinics, companies, private homes, educational institutions, and community health centres.

The two-year, credit-based program prepares individuals with the theory and skills required to work as a practical nurse, with the potential for career advancement and job mobility.

Offered on two campuses ( 32 yearly in Nanaimo; 24 every other year at Cowichan-even \# years)

Graduates of the program are eligible to write the Canadian Practical Nurse Registration Examination (CPNRE) to apply for licensure to become a Licensed Practical Nurse in British Columbia.

\section{COST: $\$ 18, \mathbf{5 7 3 . 6 4}$}

Total Credits: $\mathbf{7 5 . 5}$

(Private Program Comparison - Sprott-Shaw: \$32, 505.88)

Faculty
Chair, Instructors (2), Lab Resource
Nurse
Prepared at Bachelor level for Nursing;
Chair has MA

Appendix A: Mapping RN and LPN Education within one University (Butcher, 2017)

From Walking on Unstable Ground: A Methodologically Plural Approach to Exploring Registered Nurses' and Licensed Practical Nurses' Experiences of Learning to Work Together, by D. L. Butcher, 2017, University of Victoria [PhD dissertation]. Copyright 2017 by D.L. Butcher. Reprinted with permission.

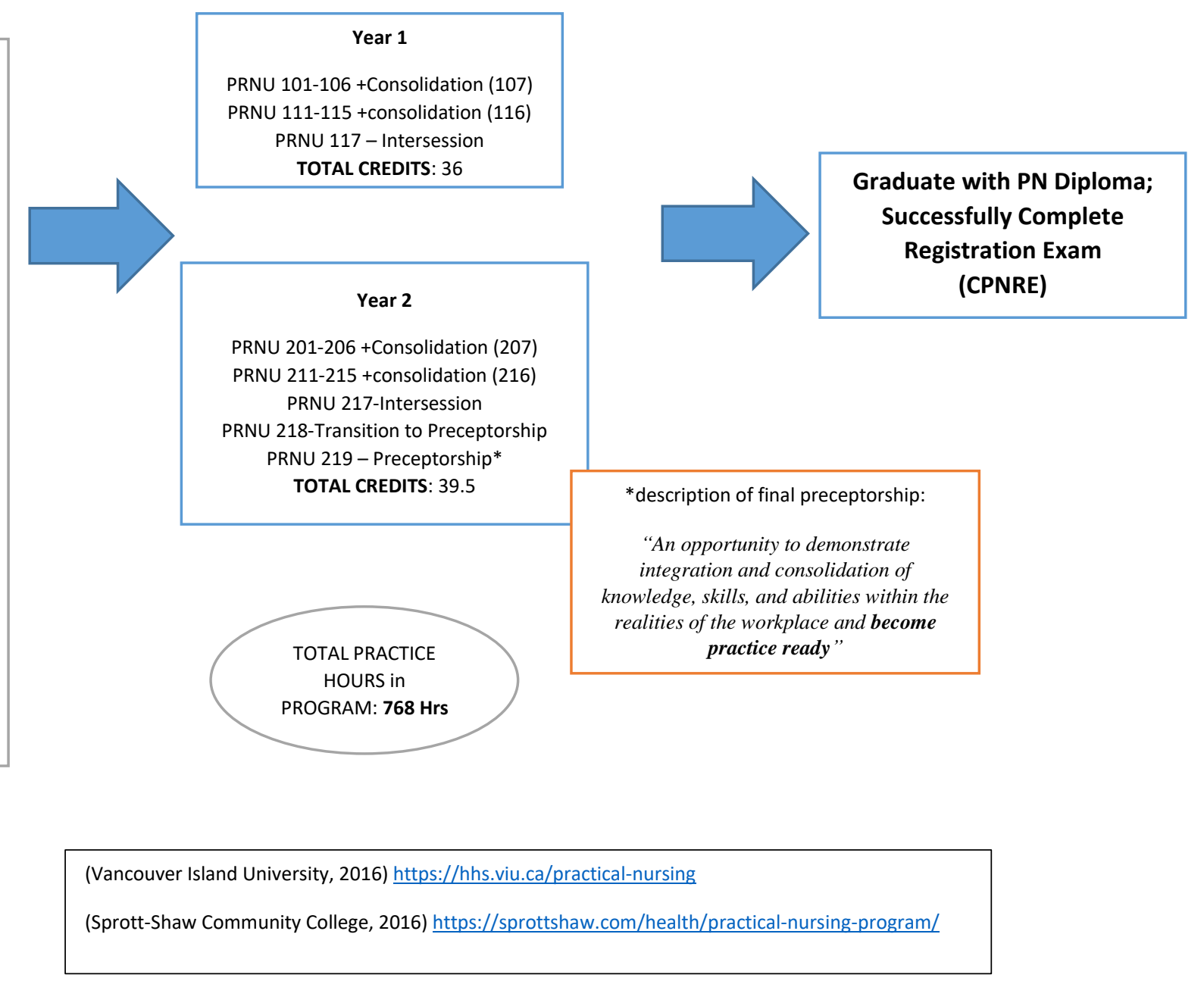




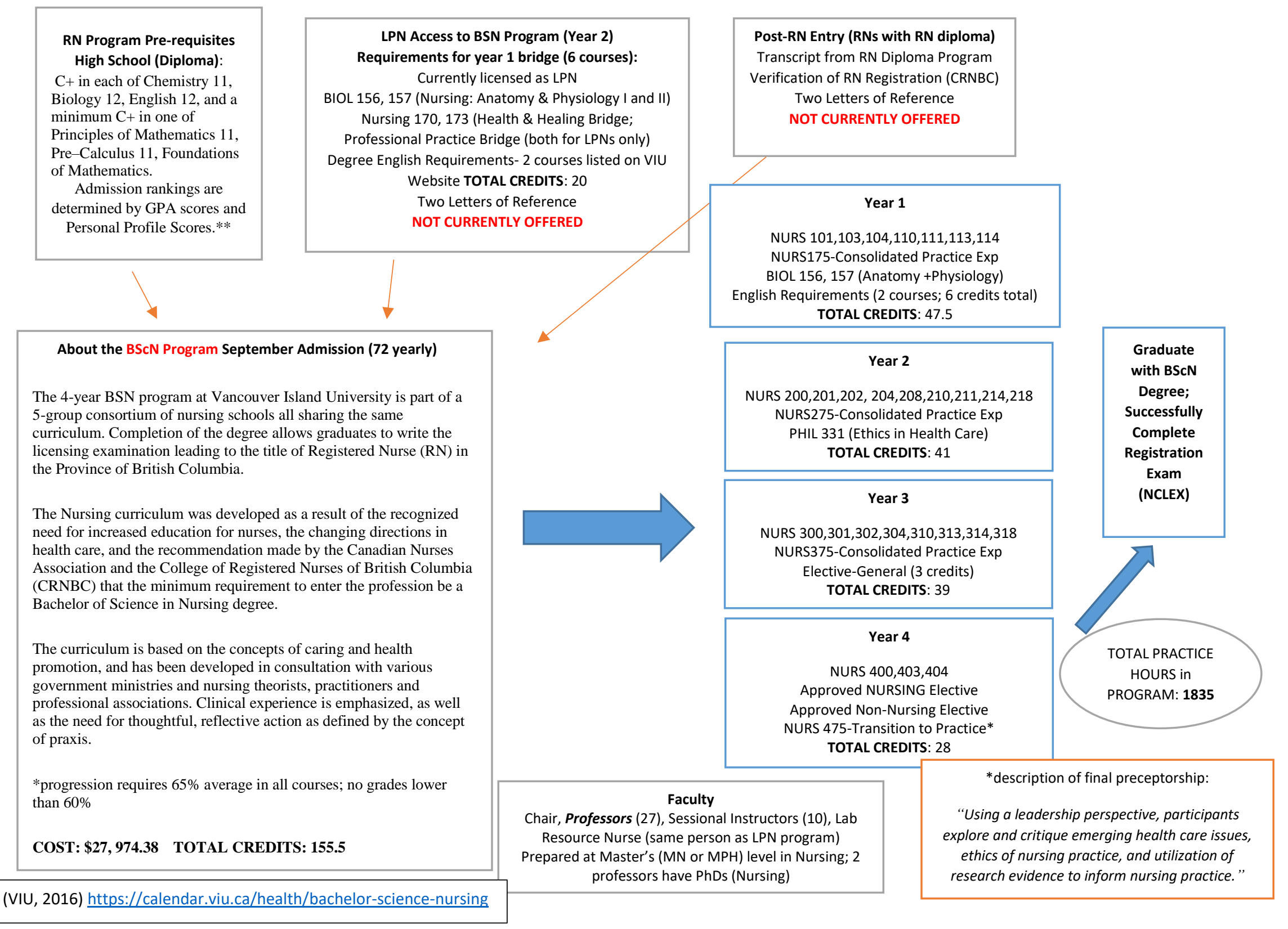


Appendix B: Boss Texts \& Institutional Discourses (Butcher, 2017)

From Walking on Unstable Ground: A Methodologically Plural Approach to Exploring Registered Nurses' and Licensed Practical Nurses' Experiences of Learning to Work Together, by D. L. Butcher, 2017, University of Victoria [PhD dissertation]. Copyright 2017 by D.L. Butcher. Reprinted with permission.

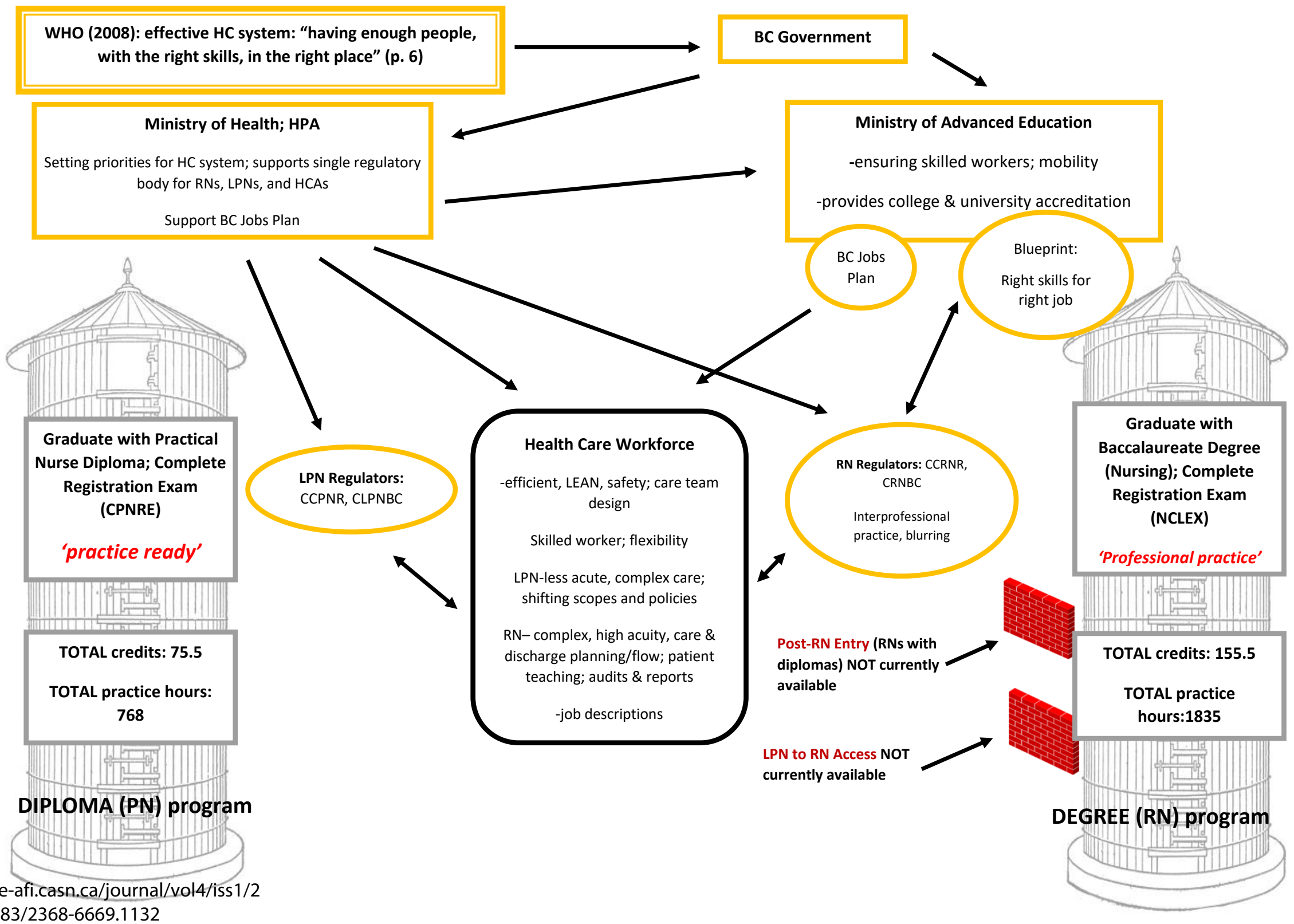

